\title{
Selenium profile in blood plasma of grazing sheep: A case study in specific ranch in Punjab, Pakistan
} \author{
Farhad Mirzaei ${ }^{5^{*}}$ \\ ${ }^{1}$ Department of Biological Sciences, University of Sargodha, Sargodha, Pakistan \\ ${ }^{2}$ Department of Botany, University of Agriculture, Faisalabad, Pakistan \\ ${ }^{3}$ Department of Chemistry, University of Sargodha, Sargodha, Pakistan \\ ${ }^{4}$ Department of Nutrition, University of Agriculture, Faisalabad, Pakistan \\ ${ }^{5}$ Department of Animal Production \& Management, Animal Science Research Institute, Iran; \\ *Corresponding Author: farmir2001@gmail.com
}

Zafar Iqbal Khan ${ }^{1}$, Kafeel Ahmad ${ }^{2}$, Muhammad Danish ${ }^{3}$, Muhammad Aslam Mirza $^{4}$,

Received 3 March 2012; revised 9 April 2012; accepted 11 May 2012

\section{ABSTRACT}

A survey was conducted in Southwestern, Punjab, Pakistan during two different seasons to assess the status of selenium of three different classes of grazing sheep. Blood plasma from lactating, non-lactating and male sheep were collected four times monthly in winter and summer seasons and analyzed for selenium concentration. Seasonal variations were found for plasma selenium concentration. Selenium concentration of plasma was higher in male sheep than those lactating and non lactating ewes during both the seasons as well as it were higher compared to the established critical value for blood plasma selenium for these ruminants. High incidence of deficiencies was found particularly for lactating ewes. These deficiencies in plasma selenium based on critical level were $35 \%$ to $15 \%$ for lactating, $28 \%$ to $12 \%$ for non lactating ewes and $15 \%$ to $5 \%$ for male animals during winter and summer seasons, respectively. Although some differences among the three classes of sheep were found for selenium concentrations of blood plasma, but dramatic class differences could not be concluded based on this study. It was suggested based on the results obtained, pellets, glass bolus or mixture that contain selenium, should be used for supplementation for grazing sheep in the study area to maintain the plasma Se at optimum required level for the prevention of complication in livestock caused due to deficiency of this element.

Keywords: Selenium; Grazing Sheep; Soil; Forage; Plasma

\section{INTRODUCTION}

Selenium is one of the essential micro minerals of the bodies of living organisms. It is required for various body functions such as growth, reproduction, immune system and protection of tissue integrity and coordination in various parts of the body. Biological functions associated with Se are to protect biological membranes from oxidative damage from free radicals. Deficiency of this element in the body results in tissue break down and degeneration [1-3]. For ruminant, requirements the suggested Se concentration is $0.10 \mathrm{ppm}$ [4]. The difference between the minimum required level and maximum tolerable level (2 ppm) is rather small. The Se metabolism is influenced by many elemental interactions. It has also been reported that different diseases have resulted from livestock grazing forages with excess Se in the range of 5 to $40 \mathrm{ppm}$ [1] .

Deficiencies in ruminants have been confirmed under natural grazing conditions in most parts of the world [2, 3]. For grazing livestock the Se deficiency is more important than its toxicity in most parts of the world $[1,3]$.

Dietary intakes of selenium have been associated with a range of biochemical functions and diseases in animals. Many of these diseases and biochemical responses can be associated with changes in expression and activity of proteins that control Se as selenocysteine at the active site [5]. Selenium performs its functions mainly through selenoproteins.

Most of the information on Se further related to its role as a component of glutathione peroxides and deiodinases. The principal constituents of plasma Se is selenoprotein-P, it contributes to Se transportation has a redox function, and may protect cell membranes [6]. Selenoprptein-P also has a potential to complex heavy metals [7]. A closely linked function of Se with vitamin $\mathrm{E}$ is to protect oxidative degeneration of biological mem- 
branes.

Degeneration of striated and skeletal muscles is commonly referred to a white muscle disease, the major outward sign of Se deficiency in newly born ruminants and many developing in utero or shortly afterbirth [8]. The various complications have been reported to be arised due to deficiency of Se in newborn ruminants which may seriously reduce the profit margin of the farmers or stockers in different parts of the world [9]. Therefore, Se requirement can be fulfilled through supplementation to grazing ruminants to prevent the complications or disorders caused due to its imbalance in various classes of ruminants.

Keeping in view the importance of selenium to livestock, this investigation was carried out evaluate the selenium status of grazing sheep in order to formulate an adequate and balanced mineral supplementation. This information would be used for Pakistan and other countries of Asia with similar ecological and climate.

\section{MATERIALS AND METHODS}

Blood samples from the jugular vein of the animals were collected into $10 \mathrm{ml}$ heparinized tubes and cooled immediately; plasma was separated by centrifugation and stored at $-20^{\circ} \mathrm{C}$ until analysis. Forage, feed, and fecal samples were dried at $60^{\circ} \mathrm{C}$ for $48 \mathrm{~h}$ and ground to fine powder using a ring grinder. Blood plasma samples were collected from grazing sheep during winter and summer seasons. For each season, collections were made four times. For sampling purpose, 30 animals were grouped into 3 classes, according to age, physiological status and gender, with 10 animals per class as follows: Class 1 contained 10 lactating sheep, class 2 comprised 10 nonlactating sheep, and class 3 consisted of 10 male sheep. These animals were ear tagged at this ranch. The forage Se concentrations (Table 1) have previously been re- ported by Khan [10]. Methods of sample collection, pasture description, animal management, and sample preparation for analysis, Se determination determined by fluorometric method [11] and data were analyzed using a split-plot completely randomized design [12]. Differences between means were ranked using Duncan's New Multiple Range Test [13].

\section{RESULTS}

Mean plasma selenium concentrations of different sheep classes related to area and sampling season are presented in Table 2. Seasonal $(\mathrm{P}<0.05)$ and animal class differences $(\mathrm{P}<0.01)$ were found for plasma selenium, with concentrations in the summer season higher than those in winter season. In either season, however, plasma selenium concentrations for all classes of grazing sheep were found to be above the critical level. Variations $(\mathrm{P}<0.05)$ in plasma Se were also found due to interactions of season and class of animal. In male animals the plasma selenium was higher compared to lactating and non lactating ewes during both seasons. The percentage of selenium deficient plasma samples in the lactating ewes was 35\% and 15\% during winter and summer seasons, respectively. However $28 \%$ and $12 \%$ of samples analyzed for winter and summer seasons for non lactating ewes and $15 \%$ and $5 \%$ of samples in male sheep for winter and summer seasons were found to be deficient in plasma selenium concentrations.

\section{DISCUSSION}

The plasma Se concentrations were higher during summer season than during the winter season. However, the average concentration for all of these classes of sheep in each season was above the critical level of $0.03 \mathrm{mg} / \mathrm{l}$ [14]. The higher plasma Se level was found in male sheep than those in lactating and non-lactating ewes dur-

Table 1. Forage selenium concentrations $(\mathrm{mg} / \mathrm{kg})$ during winter and summer at sheep ranch.

\begin{tabular}{ccccc}
\hline Season & Mean & SE & Deficient (\%) $^{\text {Critical value }^{\mathrm{a}}}$ \\
\hline Winter & 0.113 & 0.05 & 50 & $0.1-0.2 \mathrm{mg} / \mathrm{kg}$ \\
Summer & 0.092 & 0.002 & 92 & 0 \\
\hline
\end{tabular}

Means based on 24 numbers of samples of forages in each season at sheep ranch; ${ }^{a}$ : NRC (1985).

Table 2. Blood plasma selenium concentrations (mg/L) as related to season and animal class of sheep.

\begin{tabular}{|c|c|c|c|c|c|c|c|c|c|c|}
\hline \multirow{3}{*}{ Season } & \multicolumn{9}{|c|}{ Animal class } & \multirow[b]{2}{*}{ Significance } \\
\hline & \multicolumn{3}{|c|}{ Lactating } & \multicolumn{3}{|c|}{ Non lactating } & \multicolumn{3}{|c|}{ Male } & \\
\hline & Mean & SE & $\begin{array}{c}\text { Deficient } \\
\text { (\%) }\end{array}$ & Mean & SE & $\begin{array}{c}\text { Deficient } \\
\text { (\%) }\end{array}$ & Mean & SE & $\begin{array}{c}\text { Deficient } \\
(\%)\end{array}$ & \multirow{3}{*}{$\begin{array}{l}\mathrm{S}^{*} \\
\mathrm{~A}^{* *} \\
\mathrm{SA}^{*}\end{array}$} \\
\hline Winter & 0.063 & 0.07 & 35 & 0.042 & 0.02 & 28 & 0.083 & 0.03 & 15 & \\
\hline Summer & 0.12 & 0.01 & 15 & 0.085 & 0.01 & 12 & 0.114 & 0.02 & 05 & \\
\hline
\end{tabular}

Means based on 40 numbers of samples in each season for each class of sheep; $\mathrm{S}^{*}$ : Season; $\mathrm{A}^{* *}$ : Animal; SA ${ }^{*}$ : Season $\times$ Animal interaction. 
ing both seasons. This low level of plasma Se in lactating sheep.

may be attributed to the secretion in milk and feces in higher concentrations. Selenium content of the forage showed seasonal fluctuations and were higher during winter than those during summer, with $57 \%$ of the samples during the winter and $90 \%$ of the samples during the summer season were found to be deficient (Table 1). According to the requirement of $0.1 \mathrm{mg} / \mathrm{kg}$ value for sheep [15], but plasma Se levels tended to be higher during the summer season in animals despite the lower concentration of forage Se during this season. Se concentration in plasma did not reflected dietary Se intake in the present investigation (Table 2). The physiological status of the animals also seemed to be important. The elevation and depression of plasma Se is the result of availability of Se through gastrointestinal tract of animals during different seasons. Similar levels of plasma Se with seasonal fluctuations have earlier been reported in different classes of animals [16-18]. It is known that certain factors affect the Se metabolism at the absorption level. It is known when Ca level in the diet is high, as found in similar study, at this ranch $[3,16]$, it interacts with Se and interferes with its absorption $[8,14]$. The low level of Se in plasma in winter may have been possibly due to higher $\mathrm{Ca}$ in forage during winter than that in summer. The presence of heavy metals in soil and plants, and animal genetic potential are also important in Se metabolism. The amount of heavy metals in diet was also higher in winter found during similar study by Khan [10], at this ranch, which could be the possible explanation of low plasma Se in this season [19].

The animals showed a falling trend of selenium during winter season. According to McDowell [14], the selenium requirement in an animal body increases with an increased body mass. Besides, some climatic factors has a negative impact on dietary selenium concentration [7], although selenium content of forage species examined previously at this ranch was sufficient in this season. Therefore, low blood selenium concentration of animals could probably be a result of the high requirement of animals. In many regions of the world where Se-responsive diseases in livestock does not occur, the pastures and forages mostly contain at least $0.1 \mathrm{mg} / \mathrm{kg}$ Se which In areas with a variable incidence of such diseases, the contents are generally below $0.05 \mathrm{mg} / \mathrm{kg}$ and may be as low as $0.02 \mathrm{mg} / \mathrm{kg}$ [8]. In conclusion, despite the adequate amounts of selenium in the dietary sources, the animals had plasma selenium lower almost at marginal deficient level.

\section{CONCLUSION}

Plasma Se content varied considerably due to seasonal change, but it did not seem to be affected by the dietary intake. However, diet should be continually supplemented to complement the forage Se concentrations during both seasons. It is concluded that no changes in feed and plasma Se were found with respect to seasons except forage in summer and winter. These results showed no apparent animal class trends with respect to plasma Se during both seasons. The overall status may be considered adequate mainly due to the free choice mineral supplements. Short-term exposure of sheep to Se-fertilized forage results in increased whole blood Se concentrations sufficient to maintain adequate concentrations throughout grazing periods when there is limited access to Se supplements. Targeted grazing of Se-fertilized forage provides another tool for sheep producers to maintain and improve the health and productivity of their flocks, particularly when seasonal grazing practices result in limited access to Se containing salt-mineral mixes for extended periods of time.

\section{REFERENCES}

[1] McDowell, L.R. (1992) Minerals in animal and human nutrition. 2nd Edition, Academic Press, San Diego.

[2] McDowell, L.R., Conrad, J.H. and Hembry, F.G. (1993) Mineral for grazing ruminants in tropical regions. University of Florida, Gainesville.

[3] Khan, Z.I., Ashraf, M., Hussain, A., Koyro, H.W. and Huchzermeyer, B. (2005) Seasonal variation in selenium status of different classes of grazing goats in a semi-arid region of Pakistan. Deutsche Tierarztliche Worchenschrift, 112, 460-465.

[4] NRC (1996) Nutrient requirements of domestic animals. Nutrient requirements of beef cattle. 7th. Edition, National Academy of Sciences-National Research Council, Washington DC.

[5] Arthur, J.R. and Beckett, G.T. (2000) Trace elements in man and animals-10. In: Roussel, A.M., Anderson, R.A. and Fraurier, A.E., Eds., Trace Elements in Man and Animals 10, Kluwer Academic/Plenum Publishers, New York, 848.

[6] Burk, R.F. and Hill, K.E. (2000) Trace elements in man and animals-10. In: Fisher, P.W., Labbe, M.R., Cockell, K.A. and Gigson, R.S., Eds., Trace Elements in Man and Animals 10, 10th Edition, Kluwer Academic/Plenum Pubkushers, New York, 837.

[7] Underwood, E.J., and Suttle, N.F. (1999) The mineral nutrition of livestock. 3rd Editon, CAB International, Wallingford.

[8] McDowell, L.R. (2003) Minerals in animal and human nutrition. 2nd Edition, University of Florida, Gainesville.

[9] Pirelli, J.J., Weedman, S. and Weber, D.W. (2000) Beef production for small farm. Oregon State University, Corvallis.

[10] Khan, Z.I. (2003) Effect of seasonal variation on the availability of macro- and micro, nutrients to animals (sheep and goats) through forage from soil. Ph.D. Thesis, 
University of Agriculture, Faisalabad.

[11] Whetter, P.A. and Ullrey, D.E. (1978) Improved fluorometric method for determining selenium. Journal of the Association of Official Analytical Chemists, 61, 927-930.

[12] Steel, R.G.D. and Torrie, J.H. (1980) Principles and Procedures of Statistics: A biometrical approach. 2nd Edition, McGraw-Hill Inc., New York.

[13] Duncan, D.B. (1955): Multiple range and multiple F-test. Biornetrics, 11, 1-42. doi: $10.2307 / 3001478$

[14] McDowell, L.R. (1985) Nutrition of grazing ruminants in warm climates. Academic Press, New York.

[15] NRC (1985) Nutritrient requirements of domestic animals. Nutrient requirements of sheep. 6th Edition, National Academy of Science-National Research Council, Washington DC.

[16] Prabowo, A., McDowell, L.R., Wilkinson, N.S., Wilcox,
C.J. and Conrad, J.H. (1991) Mineral status of grazing cattle in South Sulawasi, Indonesia. 2-microminerals. Asian-Australasian Journal of Animal Sciences, 4, 121130.

[17] Khan, Z.I. (2003) Effect of seasonal variation on the availability of macro-and micro, nutrients to animals (sheep and goats) through forage from soil. Ph.D. Thesis, University of Agriculture, Faisalabad.

[18] Tejada, R., McDowell, L.R., Martin, F.G. and Conrad, L.H. (1987) Evaluation of the macro mineral and crude protein status of cattle in specific regions in Guatemala. Nutrition Reports International, 35, 989-998.

[19] Gerloff, B.F. (1992) Effect of selenium supplementation on dairy cattle. Journal of Animal Science, 70, 39343940. 